\title{
The ins and outs of muscle stem cell aging
}

\author{
Andrew S. Brack ${ }^{1 *}$ and Pura Muñoz-Cánoves ${ }^{2^{*}}$
}

\begin{abstract}
Skeletal muscle has a remarkable capacity to regenerate by virtue of its resident stem cells (satellite cells). This capacity declines with aging, although whether this is due to extrinsic changes in the environment and/or to cell-intrinsic mechanisms associated to aging has been a matter of intense debate. Furthermore, while some groups support that satellite cell aging is reversible by a youthful environment, others support cell-autonomous irreversible changes, even in the presence of youthful factors. Indeed, whereas the parabiosis paradigm has unveiled the environment as responsible for the satellite cell functional decline, satellite cell transplantation studies support cell-intrinsic deficits with aging. In this review, we try to shed light on the potential causes underlying these discrepancies. We propose that the experimental paradigm used to interrogate intrinsic and extrinsic regulation of stem cell function may be a part of the problem. The assays deployed are not equivalent and may overburden specific cellular regulatory processes and thus probe different aspects of satellite cell properties. Finally, distinct subsets of satellite cells may be under different modes of molecular control and mobilized preferentially in one paradigm than in the other. A better understanding of how satellite cells molecularly adapt during aging and their context-dependent deployment during injury and transplantation will lead to the development of efficacious compensating strategies that maintain stem cell fitness and tissue homeostasis throughout life.
\end{abstract}

\section{Background}

Stem cells are essential for the maintenance and repair of many adult tissues during normal physiology or in response to damage. Operationally defined, stem cells produce daughter cells that differentiate to repair damaged tissue and self-renew to repopulate the stem cell pool. Although long lived, tissue resident stem cells do not retain their fitness and function indefinitely. The unique requirement of tissue resident stem cells to maintain themselves and form new specialized cells may explain why their decline has a greater detrimental impact than that of other cell types on tissue regeneration. Across different stem cell compartments, age-dependent changes that cause stem cell dysfunction are multifactorial, encompassing, systemic, local, and intrinsic factors [1].

Adult stem cells have tissue-specific properties, related to the tissue they serve, such as distinct rates of turnover and specialized differentiation programs. Yet, they also have many common characteristics. They transit between

\footnotetext{
*Correspondence: asbrack1@gmail.com; pura.munoz@upf.edu

'Department of Orthopaedic Surgery, Eli and Edythe Broad Center of Stem

Cell Research and Regeneration Medicine, University of California San

Francisco, 35 Medical Way, San Francisco, CA 94143, USA

${ }^{2}$ Department of Experimental and Health Sciences, Pompeu Fabra University, ICREA and Ciberned, Dr. Aiguader, 88, E-08003, Barcelona, Spain
}

quiescence and activation stages, their chromatin adopts bivalent states to facilitate rapid differentiation of selfrenewal, they are capable of undergoing symmetric and asymmetric divisions, their metabolism is specialized to adapt to their particular needs, and they are located within microenvironments which influence their functions $[2,3]$. These specific and common traits intertwine with general aging mechanisms resulting in distinct phenotypes over time.

During aging, many tissues undergo changes in stem cell number and function that impact tissue homeostasis. Optimal stem cell function necessitates appropriate extrinsic support from the local microenvironment (niche) and systemic environment (circulation). Hence, aging of the stem cell local and systemic environment is pertinent to stem cell demise. Since the original demonstration using parabiosis that muscle repair was under the control of soluble factors present in serum, alterations in the composition of the systemic environment has been the prevailing model to explain defects in skeletal muscle repair during aging $[4,5]$. With aging, it has also been shown that niche cells no longer provide appropriate growth factor support, thus altering their behavior. Inflammation, which increases in the aging circulation and niche, also impacts negatively stem cell functions [6-8]. 
Satellite cells constitute the principal stem cell pool of adult skeletal muscle. Genetic ablation studies and transplantation studies together confirm that Pax7+ satellite cells are sufficient and required for adult muscle repair [9-11]. In response to muscle damage, satellite cells transition from their normally quiescent state, enter the cell cycle, and expand and differentiate (exit the cell cycle) to form new muscle fibers and regenerate the injured muscle tissue [12]. In aged mice, muscle repair is blunted in a large part due to satellite cell dysfunction [13-18]. However, stem cell decline does not contribute relevantly to the age-related reduction of myofiber size (sarcopenia) in the absence of muscle damage [19].

Unlike other types of stem cells, such as hematopoietic stem cells, not only the function but also the number of satellite cells declines with aging $[13,14,20]$. In aged muscle, the number of stem cells can become limiting for regenerative capacity [13]. It is likely that there exists a quorum of muscle stem cells to effectively repair muscle, and the number will differ depending on the fitness of the cells and the environmental support.

At variance with other types of stem cells, information regarding the molecular pathways promoting aging of satellite cells is abundant. Parabiosis and whole muscle grafting experiments reveal that the mechanisms controlling the regeneration capacity of stem cells may be principally ascribed to changes in the aging environment [4, 21-23]. However, more recent data from studies using transplantation of purified satellite cells demonstrates that stem cell dysfunction during aging has a cell-intrinsic component [13-16].

In this review, we discuss what is known about the principal stem cells of skeletal muscle, focusing on the control of stem cell function from the extrinsic environment and intrinsic regulation. We specifically consider what degree of stem cell dysfunction can be ascribed to the age-associated changes in the environment, cellautonomous changes, or both, what makes satellite cells more or less susceptible to aging; and whether this can shed light on potential rejuvenating strategies.

\section{Muscle stem cell function and the aging environment}

The influence of the extrinsic environment on the efficiency of the regeneration process arouse from whole muscle transplantation experiments and parabiosis. Transplantation of whole muscle grafts of young and old mice showed that the regenerative ability of young and old muscles depended mainly on the age of the host, as young hosts allowed successful engraftment of both young and old muscles while both graft types failed to regenerate in old rats [24]. However, further studies showed delayed regeneration in old muscle grafts even in a youthful environment $[7,8]$. This was ascribed to the altered inflammatory cell function at old age [25]. In agreement with these results, studies by Lee et al. [26], using different paradigms of muscle regeneration, support a delay rather than impairment in muscle regeneration at old age. More recent studies have shown, however, that whole muscles from geriatric mice (28 months of age or older) grafted onto young recipient muscles maintain a regenerative defect [14]. In support, Chakkalakal et al. compared muscle repair 30 days after $\mathrm{BaCl}_{2}$-induced muscle injury and observed that muscle fiber size did not return back to pre-injured levels in aged mice [13]. Possibly, the differences in the extent of regeneration among these studies might be due to the distinct ages, gender of mice, and models of muscle injury employed. It is noteworthy that even if repair of muscle is delayed rather than impaired, the rate at which an aged human tissue recovers after injury or surgery will have significant ramifications for their health and general well-being.

Parabiosis has been used to test the effects of circulatory or systemic factors of one animal on the other for over 100 years [5]. Anastomosis of the circulatory system between adult and old mice provided definite evidence that the effects of aging on muscle regeneration can be modulated by the age of the systemic environment [4]. Based on short-term injury-repair models, youthful factors accelerated muscle repair, and aging factors delayed repair [4]. In vitro cell culture experiments supported this observation at the level of the satellite cell and their progeny $[4,27]$. This seminal work paved the path to the discovery of circulating factors as regulators of satellite cell aging. Numerous studies have now shown that aged muscle repair can be augmented by modulation of many signaling pathways including RTK/ERK, Notch, Wnt, TGF $\beta$, and hormones, such as oxytocin, in vivo [23, 27-30]. Importantly, neutralization of Wnt and TGF $\beta$ signaling in old mice restored efficient muscle repair. It is worth noting that both signaling pathways antagonize Notch signaling, which is critical for satellite cell activation, proliferation, and self-renewal [23, 27, 31]. In addition, treatment of aged mice with the reproductive hormone oxytocin promotes muscle regeneration [28]. In sum, targeting cell-extrinsic regulators in old mice, via parabiosis (or exposure to factors in young serum in cell culture), via inhibition of Wnt and TGF $\beta$ signaling, or oxytocin administration, significantly rescues defective satellite cell-mediated muscle regeneration.

Recently, the assessment of the expression and role of a circulating factor, growth differentiation factor 11 (GDF11), has provided conflicting results $[32,33]$. The results from the first study implied that circulating GDF11 levels decline with aging and showed that the treatment of old mice with recombinant GDF11 improved muscle regeneration after injury [33]. A subsequent study showed that GDF11 levels do not decline with aging and that administration of recombinant GDF11 protein does not affect repair of 
old muscle [32]. The reasons for the discrepancies are discussed elsewhere [34].

Overall, these findings demonstrate reversibility of satellite cell dysfunction in old animals through restoration by, or mimicking of, a young extrinsic environment. Due to the nature of the muscle injury assay, and the influence of many cell types to its outcome, it is not possible to determine if these stimulatory effects are acting at the level of the stem cell, myogenic progenitors, or different cell types. Indeed, direct evidence for non-stem cell-mediated control of muscle repair comes from studies investigating inflammation. A transient blood-mediated inflammatory response to muscle injury is key for successful regeneration $[35,36]$. Paradoxically, organismal inflammation increases during aging [37]. Yet, the initial inflammatory response to muscle injury in old mice is delayed [7]. This, together with the increased production of osteopontin by old macrophages infiltrating injured muscle, could contribute to the poor regenerative outcome of aged muscle [30]. Indeed, neutralization of osteopontin rejuvenated the behavior of old satellite cells in vivo and in vitro, reinforcing the idea that age-related inflammatory responses become counterproductive for muscle regeneration. Furthermore, recent studies have shown a detrimental role for IL-6-Jak-Stat3 signaling [17, 18]. Thus, while transient inflammation in response to muscle injury is required for efficient regeneration, chronic elevation may be deleterious $[17,18]$. Finally, a recent report showed that the increased levels of TGF $\beta$ in aged mice promoted inflammation, rather than exerting its canonical role in attenuating immune responses, and hence inhibition of TGF $\beta$ signaling improved regeneration [31]. Interestingly, increased levels of TGF $\beta$ have been recently shown to promote survival of fibroadipogenic progenitors (FAPs), a muscle-resident mesenchymal stomal cell population known to crosstalk with satellite cells during acute muscle regeneration in young mice [38]. Therefore, increased TGF $\beta$ in aged environment may have deleterious functions on satellite cells through an increase in pro-fibrotic muscleresident stem cell types.

\section{Muscle stem cell aging at the cell-autonomous level}

In more recent years, the direct assessment of muscle stem cell potential via transplantation has become more commonplace. Stem cell transplantation was pioneered by Till and Mcullough 55 years ago [39, 40]. Today it is considered the gold standard assay to examine stem cell potential. A cell possessing stem cell properties will be able to proliferate and self-renew to repopulate the stem cell compartment and produce differentiated daughter cells in a viable recipient tissue. The standard transplantation approach involves the enrichment/purification of stem cells within a tissue by antibody detection against cell surface receptors, or fluorescent reporters of cellspecific gene expression. It is imperative that the donor stem cell is indelibly marked to distinguish the donor from the recipient.

Injection of tractable adult satellite cells as a population, and at the single cell level, has provided definite evidence for their stem cell status, based on the ability to proliferate, differentiate (fuse to recipient pre-injured muscle), and self-renew (reoccupy the niche and express satellite cell markers). Comparisons between purified satellite cells from adult and aged mice transplanted into pre-injured adult muscle show a substantial decline in the number of aged satellite cells that repopulate the niche and contribute to muscle fiber differentiation (Table 1). In agreement, engraftment of single muscle fibers (with their complement of satellite cells) from adult and aged mice into recipient adult muscle demonstrated an age-dependent decline in satellite cell engraftment and niche repopulation [15]. In contrast, Collins et al. demonstrated that satellite cell niche repopulation was comparable between adult and aged engrafted muscle fibers [41]. While different methodologies have been employed, which hinder direct comparison, on balance, it is clear that aged satellite cells are less capable of niche repopulation and differentiation under the context of transplantation into an adult host. This is consistent with numerous earlier studies that showed aged satellite cells and their progeny were less capable of proliferating and differentiating in 'optimized' growth conditions in vitro [12, 42, 43].

Over the past few years, it has become apparent that functional heterogeneity exists within the satellite cell pool [13, 44-46]. Therefore, any functional decline in the aged satellite cell pool under transplantation conditions might exist through a relative loss of competent cells rather than the uniform loss of function across the total pool. Using a TetO-H2B-GFP reporter to quantify proliferative output, it is apparent that based on the retention (label retaining cells; LRCs) or loss of GFP label (non-LRCs; nLRCs), the adult satellite cell pool is composed of cells that undergo distinct proliferative histories during postnatal growth and regeneration [13]. Examined under transplantation, LRCs are able to self-renew and differentiate, and nLRC are limited to differentiation. Therefore, LRCs act as stem cells and nLRCs as committed progenitors. It is estimated that there are $\sim 65 \%$ fewer LRCs in aged versus adult muscle [13]. Importantly, the remaining LRCs in aged muscle retain a similar level of tissue engraftment and contribution as adult LRCs, i.e., they are age-resistant. Cosgrove examined satellite cell function in transplantation assays under a limiting dilution series, whereby satellite cells ranging from 10 to 100 were injected into a pre-irradiated, pre-injured adult muscle [16]. It was calculated that aged muscle contains $~ 65 \%$ 
Table 1 Reports of age-related changes in muscle stem cell function based on purified satellite cell and single muscle fiber transplantation assays

\begin{tabular}{|c|c|c|c|c|c|c|c|c|c|}
\hline Age of donor & $\begin{array}{l}\text { SC or single } \\
\text { fiber transplant }\end{array}$ & $\begin{array}{l}\text { Cell number } \\
\text { and purification }\end{array}$ & $\begin{array}{l}\text { Genotype and } \\
\text { age of recipient }\end{array}$ & IR host & Muscle injury & Method of detection & Analysis timepoint & $\begin{array}{l}\text { Change in SC function } \\
\text { (aged relative to adult) }\end{array}$ & Ref. \\
\hline 4 vs $24 \mathrm{~m}$ & SC & $\begin{array}{l}2000 \text { Lin-VCAM+, } \\
\text { INT-A7 }\end{array}$ & $4 \mathrm{~m} \mathrm{C57Bl6}$ & No & $\mathrm{BaCl}_{2}$ & $\begin{array}{l}\text { H2B-GFP marked } \\
\text { nuclei per muscle }\end{array}$ & $30 \mathrm{dPI}$ & $\begin{array}{l}\text { SC and myofiber: } \\
40 \% \text { decline }\end{array}$ & {$[13]$} \\
\hline $5,22,30 \mathrm{~m}$ & SC & $\begin{array}{l}\text { 10,000 FACS: } \\
\text { Lin-CD31+/INT-A7 }\end{array}$ & $4 \mathrm{~m} \mathrm{NOD/SCID}$ & No & CTX & Lentiviral GFP & $21 \mathrm{dPI}$ & Myofiber: $70 \%$ decline & [14] \\
\hline 2 vs $24 \mathrm{~m}$ & SC & $\begin{array}{l}\text { 10-100 (limiting } \\
\text { dilution series) FACS }\end{array}$ & $2 \mathrm{~m} \mathrm{NOD/SCID}$ & Yes & CTX & GFP/Luc or Myf5lacz & $30 \mathrm{~d} / 60 \mathrm{dPI}$ & $\begin{array}{l}100 \text { SCs: not different. } \\
10 \text { SCs: } 30 \% \text { decline } \\
\text { in SC }\end{array}$ & {$[16]$} \\
\hline 3 vs $18 \mathrm{~m}$ & SC & 10,000 Pax7-Zs-green & $2-4 m m d x$ & No & Natural turnover + CTX & $\begin{array}{l}\text { Pax-Zs-green and } \\
\text { dystrophin antibody }\end{array}$ & $21 \mathrm{dPI}$ & $\begin{array}{l}\text { SC: } 70 \% \text { decline; } \\
\text { myofiber: } 50 \% \text { decline }\end{array}$ & {$[17]$} \\
\hline 4 vs $26 \mathrm{~m}$ & Single fiber & 5-7 muscle fibers & 4 m C57Bl6 & No & $\mathrm{BaCl}_{2}$ & SC: $\beta$-actin GFP/Pax7+ & $30 \mathrm{dPl}$ & $60 \%$ decline SC repopulation & [15] \\
\hline $1-2$ vs $22-30 \mathrm{~m}$ & Single fiber & 1 muscle fiber & $1 \mathrm{~m}$ mdx. NOD/SCID & Yes & $\begin{array}{l}\text { Natural turnove + } \\
\text { repeated CTX }\end{array}$ & $\begin{array}{l}\text { Myonuclei :3F-nlacZ-2E. } \\
\text { SC: Myf5lacZ }\end{array}$ & $30 \mathrm{~d} / 40 \mathrm{dPI}$ & SC and myofiber: not different & [41] \\
\hline
\end{tabular}

The results highlight the different approaches that have been employed to study the effect of age on satellite cell engraftment, self-renewal, and differentiation using purified satellite cell and single muscle fiber transplantation assays

Abbreviations: $\mathrm{m}$ month, $\mathrm{Lin}^{-} \mathrm{SCa1}{ }^{-} / \mathrm{CD} 31^{-} / \mathrm{Cd} 45^{-}, \mathrm{NOD} / \mathrm{SCID}$ non-obese diabetic/severe combined immune deficiency, Mdx mouse model carrying naturally occurring mutation of dystrophin gene, IR irradiation, $C T X$ cardiotoxin, $\mathrm{BaCl}_{2}$ barium chloride, $\mathrm{dPI}$ days post injury, GFP/LucZ ubiquitous readout, Myf5lacZ lacZ reporter of myf5 locus, Ref. reference 
fewer functional stem cells than adult muscle. Together, these data argue strongly that the functional decline observed in the aged satellite cell pool is due to a decrement in the number of functional stem cells.

\section{Parabiosis versus transplantation paradigms to study muscle stem cell aging}

The functional deficit of aged satellite cells engrafted in a young host in its strictest sense has been used to conclude that there is a non-reversible component to stem cell aging. However, parabiotic conditions provided only a partial recovery of muscle repair in aged mice exposed to a young systemic environment. One could consider this due to a partial dilution of aged blood; however, it could also be due to other factors outside the systemic environment, including the niche or intrinsic defects. To date, a direct comparison of aged satellite cells after engraftment in adult and aged recipients is lacking. In addition, using heterochronic parabionts to serve as the source of donor satellite cells or recipient muscle for transplantation experiments has not been examined. For example, if the functional deficit of aged satellite cells (versus adult satellite cells) engrafted into an aged host was twice that observed in a young host, the results from parabiosis, transplantation, and in vitro studies would be in general agreement: that alterations in stem cell function during aging is a product of intrinsic and extrinsic deregulation. Alternatively, if results from transplantation studies do not support an extrinsic component, in contrast to endogenous muscle cells after injury, this would highlight the context dependence of the assays employed. Another factor that limits direct comparison is the age of the mice examined. Parabiosis studies have classically been carried out on 18-month-old mice, whereas transplantation studies have predominantly used mice that are 20 months and older. As age-dependent phenotypes are progressive, this may impact the rejuvenation potential of satellite cells. Another distinction is the length of recovery after injury between the two types of studies. Acute repair processes have been studied predominantly after parabiosis, and longer recovery periods assessed in transplantation studies. Identifying the long-term injury response on parabionts would help to resolve this potential discrepancy. Finally, we cannot discard that the genotype and age of the recipient mice in cell engraftment experiments might also influence the regenerative outcome. Indeed, aged mice experience chronic inflammation, yet the inflammatory response in whole muscle grafts is less efficient with age, and this appears to impact new myofiber formation [8]. Consistent with the influence of the inflammatory status of the recipient mice, it is tempting to propose that the exacerbated inflammation of $m d x$ mice or the blunted immune response of immunecompromised mice will exert opposite, albeit impactful effects on cell engraftment.
Resolving the relative contribution of intrinsic and extrinsic control on stem cell function is critical, but it should also be considered that the assays deployed for determination are not equivalent and may overburden specific cellular regulatory processes and thus probe different aspects of satellite cell properties. The cellular experience of the stem cell pool is likely very different if activated by injury while in their resident niche, compared to the physical manipulations that take place to extract, purify, and inject satellite cells into a foreign muscle. It is likely that the isolation of satellite cells followed by their transplantation (sometimes with a prior cell culturing period) may provoke cellular changes (epigenetic, transcriptional, or other) that influence satellite cell output and tissue contribution. On the other hand, parabiosis procedure-associated complications like limitation on mice mobility, chronic inflammation (which perturbs the environment), or hypoglycemia, may account for some of the observed effects [47].

Intriguingly, in other stem cell systems, different stem cell subsets can dominate tissue contribution depending on the assay employed. Using genetic bar coding, which allowed individual hematopoietic stem cells (HSC) clones to be tracked over time, the Camargo lab found that HSC contribution during transplantation was derived from substantial expansion of rare clones [48]. In contrast, normal blood production was derived from more modest expansion of multiple clones. If this feature of stem cell diversity is conserved, one could hypothesize that a rare population of satellite cells are equipped to successfully engraft, self-renew, and differentiate under the setting of transplantation, whereas a larger fraction of the satellite cell population is equipped for robust tissue contribution during endogenous muscle repair. Hall et al. [49] examined the fate of transplanted adult satellite cells as the host aged. Analysis of aged muscle 21 months after initial satellite cell engraftment showed that that engrafted population persisted and increased their relative contribution over the host satellite cell population over time. This data suggests that the satellite cell pool contains age-resistant highly engraftable subsets. One can speculate that the properties that endow transplantation capacity and render age-resistance may overlap. In the future, it will be important to define the contribution and regulation of satellite cell subsets in distinct contexts.

\section{Loss of satellite cell functions during aging Cell-autonomous alterations}

The functional deficit of satellite cells as a feature of aging examined under transplantation suggests a strong cellintrinsic and irreversible component that could include genomic instability, DNA and oxidative damage, and alterations in mitochondrial function. Indeed, satellite cells have an increased resistance to DNA damage and capacity 
to repair DNA lesions than their committed progeny [50]. Satellite cells isolated from aged muscles show an increased number of foci containing the phosphorylated form of histone $\mathrm{H} 2 \mathrm{AX}$ ( $\mathrm{pH} 2 \mathrm{AX})$, a marker of DNA damage [14,33]. In addition, the decline in antioxidant capacity of satellite cells with aging [51] likely impacts their genomic integrity, suggesting a relevant function of DNA damage repairing mechanisms. Consistent with this, mice deficient for Ku80, a subunit in the nonhomologous end-joining pathway (NHEJ), show an accelerated aging phenotype in skeletal muscle [52]. Comparative gene expression studies from quiescent and activated satellite cells from young and old mice and humans have uncovered transcriptomic changes related with decreased antioxidant activity and altered expression of myogenic differentiation-specific genes and genes related to protein folding [41, 53-59], which could be caused by global epigenetic alterations in young and old satellite cells [58].

At the level of single genes, adult satellite cells epigenetically repress the INK4a locus that encodes $\mathrm{p} 16^{\mathrm{INK} 4 \mathrm{a}}$ (a cell cycle inhibitor and marker of senescence) via ubiquitination of histone $\mathrm{H} 2 \mathrm{~A}$, this repression is relieved in aged cells [14]. Furthermore, increasingly permissive chromatin has been detected at the $\mathrm{p} 16^{\mathrm{INK} 4 \mathrm{~A}}$ and $\mathrm{p} 21^{\mathrm{CIP} 1}$ loci, provoked by alterations in H3K4me3 and H3K27me3 chromatin marks, in aging satellite cells after injury [28].

Despite the always attractive possibility for rejuvenation as indicated by parabiosis experiments, satellite cell aging proceeds to a limiting point where it essentially becomes irreversible, particularly at the late geriatric age [14], suggesting further intrinsic changes in geriatric cells. In the quiescent state, geriatric cells express $\mathrm{p} 16^{\mathrm{INK} 4 \mathrm{a}}$, which causes loss of the G0 reversible quiescent state. In response to regenerative pressure by injury, $\mathrm{p} 16^{\mathrm{INK} 4 \mathrm{a}}$ caused the de-phosphorylation of the retinoblastoma protein $(\mathrm{Rb})$ and repression of E2F target genes in proliferationpromoting conditions, which accelerates entry into full senescence [14]. Regardless of the more or less general senescence occurrence, elimination of senescent cells through inducible targeting of $\mathrm{p} 16^{\mathrm{INK} 4 \mathrm{a}}$ has been shown to delay aging in several tissues of BubR1 progeroid mice, including skeletal muscle [60]. It remains unresolved whether the phenotypic improvement after $\mathrm{p} 16^{\text {INK4a }}$ knockdown or ablation of $\mathrm{p} 16^{\mathrm{INK} 4 \mathrm{a}}$-expressing cells is restricted to senescence modulation exclusively.

Whether the pre-senescent state of satellite cells from geriatric mice is restricted to a subset or a feature of most satellite cells is not known. However, it is tempting to propose that, as for satellite cell apoptosis, senescence might be an alternative way to restrict unfit satellite cells of aged mice from undergoing myogenesis. Supporting the notion that $\mathrm{p} 16^{\mathrm{INK} 4 \mathrm{a}}$-induced senescence can contribute to loss of satellite cells, mice overexpressing $\mathrm{p} 16^{\mathrm{INK} 4 \mathrm{a}}$, due to genetic loss of the polycomb repressor complex 1 (PRC1) protein Bmi1 $[14,61]$, or the enzymatic subunit of the polycomb-repressive complex 2 (PRC2), Ezh2 [62], showed reduced numbers of satellite cells. Progeric mice displaying premature aging also showed a depletion of the satellite cell pool, increased $\mathrm{p} 16^{\mathrm{INK} 4 \mathrm{a}}$ expression in the resting state, and pro-senescence phenotypes [14]. Interestingly, a recent report demonstrated cellular senescence in the process of adult skeletal muscle regeneration [63], suggesting that this cellular fate is not restricted to aging muscle.

\section{Extrinsically driven satellite cell alterations}

While intrinsic molecular effectors determine cell functionality, it is less clear whether they are autonomously driven or a consequence of altered extrinsic factors. The adult satellite cell pool is functionally heterogeneous, with subsets enriched for stem cell potential under transplantation conditions [13, 44, 45, 64]. During aging, there is a loss of muscle stem cells, that is associated with a decrease in Spry1 (encodes Sprouty1), an inhibitor of FGF signaling and upregulation of FGF2 in the niche. Genetic elimination of Spry1 in satellite cells enforced FGF signaling, which resulted in loss of quiescence and subsequent reduction in the satellite cell number. Spry1 elimination during adult muscle repair led to sustained activation of the ERK pathway, which impaired self-renewal and caused apoptosis in a subset of satellite cells [65]. Together, these findings reinforce an FGF-feedback regulatory mechanism for stem cell viability [13]. The critical role of Spry1 in muscle stem cell regulation is not restricted to murine studies. Myogenic progenitors from adult and aged human biopsies show increased DNA methylation at the Spry1 locus coupled with a loss of 'reserve' cells to return back to a quiescent state [66]. Demethylation of the aged cells improved self-renewal of the quiescent pool. This suggests that there may be cell-autonomous regulation of pathways classically considered extrinsically driven. It would be interesting to examine whether niche-derived growth factors can shape the epigenetic landscape of the stem cell.

The normal asymmetric divisions that produce one stem and one committed progenitor in adult satellite cells are disrupted in aged satellite cells via chronic elevation of p38 $\alpha \beta$ MAPK signaling and desensitized FGFR1 activity. Instead, aged satellite cells preferentially undergo symmetric divisions that produce two committed daughters. This limits the expansion of aged satellite cells, favoring their permanent cell cycle exit $[15,16]$. While it is not clear what drives $\mathrm{p} 38 \alpha \beta$ MAPK in aged satellite cells, niche-derived FGF2 is a feasible candidate. Bernet and colleagues propose that elevated FGF2 is a compensation strategy to remedy the loss of FGFR1 signaling [15]. Alternatively, reduced FGFR1 sensitivity may be a consequence of ligand-induced 
receptor internalization [67]. In conclusion, the FGF2p38 $\alpha \beta$ MAPK pathway has detrimental consequences on the intrinsic regenerative functions, including the restoration of the quiescent satellite cell pool through self-renewal.

Similarly, as indicated before, an increasingly active IL6-JAK/STAT3 pathway in satellite cells with age appears to reduce their regenerative potential by limiting their proliferative capacity and affecting their symmetric versus asymmetric polarization $[17,18]$. This may be linked to the higher levels of inflammatory cytokines found in aging organisms [68].

\section{Stress pathways in aged satellite cells}

It is widely appreciated that freshly isolated satellite cells from aged mice have a predisposition for apoptosis and senescence when placed in culture conditions $[13,14,16,41]$. This suggests that aged satellite cells may be less resilient in the face of exogenous stress and undergo molecular changes that limit functional output.

Recent data from multiple groups have shown a robust improvement of aged satellite cells under transplantation by various intervention strategies. Interestingly, adult satellite cells are less responsive to the same interventions. These recently identified age-related intrinsic alterations include a combination of signaling pathways associated with cellular stress, such as p38 MAPK, JAK-STAT3, and p $16^{\mathrm{INK} 4 \mathrm{a}}$. Elevation of stress pathways beyond a certain threshold can promote cellular arrest and predispose to senescence or apoptosis fates, either by inducing mitochondrial dysfunction, increasing reactive oxygen species (ROS), or DNA damage (reviewed in [69-73]). The cumulative alterations of stress-related pathways with aging, and their hyperactivation during experimental cell transplantation procedures, limit the expansive capacity and engraftment of old satellite cells and impair formation of new myofibers. Importantly, caloric restriction as a means to decrease metabolic stress improved engraftment of adult satellite cells and expansion of adult and aged satellite cells in cell culture assays [74]. Importantly, stressdependent control of stem cell function is likely conserved across species [75]. In contrast to adult human satellite cells that lose engraftment after expansion in culture, human satellite cells grown in the presence of a p38 MAPK inhibitor can proliferate in vitro and retain subsequent engraftment potential in transplantation assay [75]. Therefore, transplantation success will likely depend on the ability to adapt and survive the stress of engraftment. Because aged satellite cells may be less resilient, modulation of stress pathways could provide a robust intervention for their functional rejuvenation.

The satellite cell pool becomes more homogeneous with age, with reduced representation of cells having high regenerative potential, and increased proportion of cells with reduced clonal proliferation capacity [13]. Thus, it is likely that the functional improvement of old satellite cells by biochemical or genetic strategies in transplantation experiments results from the proliferative amplification of a minor subset of highly regenerative cells. In any case, aged satellite cells seem susceptible to the high levels of stress induced by transplantation procedures, and only attenuation of the stress (i.e., by reducing p38 MAPK, JAK-STAT signaling, or $\mathrm{p} 16^{\mathrm{INK} 4 \mathrm{a}}$-induced senescence) can allow their functional rejuvenation upon engraftment.

\section{Conclusions}

Parabiotic studies have demonstrated extrinsic components, whereas transplantation assays have confirmed intrinsic components that cause age-dependent muscle stem cell decline. At first glance, the results based on satellite cell transplantation appear to be in conflict with those from parabiosis. The main purpose of this review has been to highlight the potential causes of discrepancy among the different papers and discuss how these differences teach us new facets about muscle stem cell biology and aging. We believe that the procedure chosen to assess the capacity of the young environment to rejuvenate aged satellite cells greatly accounts for the differences. We propose that the isolation of satellite cells and their subsequent transplantation may exacerbate intrinsic changes that importantly alter their functions. Thus, stem cell potency is greatly influenced by their capacity to overcome the stress of engraftment. From this viewpoint, old satellite cells would be less resistant to this stress. Importantly, strategies that modulate stress pathways in old satellite cells constitute a robust method for functional rejuvenation. Noteworthy, acute inflammation and stress, induced by the surgical joining of two animals in parabiosis experiments, might cause systemic perturbations that could affect satellite cell functions in yet unpredictable ways. In addition, the choice of genotype and age of the recipient mice for engraftment assays might also influence the regenerative outcome.

Another issue that may contribute to the apparently discrepant results between parabiosis and transplantation experiments relies on the molecular and functional diversity within the satellite cell population. Rejuvenation of aged satellite cells, in the context of transplantation, might derive from the augmented expansion of a small subpopulation of the fitter and more stress-resistant stem cells. Whether distinct satellite cell subsets are mobilized preferentially in the context of repair and transplantation or are differentially sensitive to intrinsic and extrinsic stressors warrants testing. A greater comprehension on the causative factors that drive satellite cell dysfunction during aging will lead to strategies that promote tissue rejuvenation and a beneficial impact on the quality of life of the elderly. 


\section{Competing interests}

The authors declare that they have no competing interests.

\section{Authors' contributions}

ASB and PMC conceived and wrote the review. Both authors read and approved the final manuscript.

\section{Acknowledgements}

We thank members of the Brack and Muñoz-Cánoves labs for comments during the preparation of this manuscript. Work in the authors' laboratories was supported in part by grants from the US Institutes of National Health (R01AR060868 and R01AR061002) to ASB and by the Spanish Ministry of Economy and Innovation SAF2012-38547, SAF2015-67369-R, E-RARE, Marató-TV3, AFM, and EU-FP7 (Myoage and Endostem) to PMC.

Received: 24 November 2015 Accepted: 5 January 2016 Published online: 18 January 2016

\section{References}

1. Jung Y, Brack AS. Cellular mechanisms of somatic stem cell aging. Curr Top Dev Biol. 2014;107:405-38. doi:10.1016/B978-0-12-416022-4.00014-7.

2. Cheung TH, Rando TA. Molecular regulation of stem cell quiescence. Nat Rev Mol Cell Biol. 2013;14(6):329-40. doi:10.1038/nrm3591.

3. Oh J, Lee YD, Wagers AJ. Stem cell aging: mechanisms, regulators and therapeutic opportunities. Nat Med. 2014;20(8):870-80. doi:10.1038/nm.3651.

4. Conboy IM, Conboy MJ, Wagers AJ, Girma ER, Weissman IL, Rando TA Rejuvenation of aged progenitor cells by exposure to a young systemic environment. Nature. 2005;433(7027):760-4. doi:10.1038/nature03260.

5. Conboy MJ, Conboy IM, Rando TA. Heterochronic parabiosis: historical perspective and methodological considerations for studies of aging and longevity. Aging cell. 2013;12(3):525-30. doi:10.1111/acel.12065.

6. Franceschi C, Bonafe M, Valensin S, Olivieri F, De Luca M, Ottaviani E, et al Inflamm-aging. An evolutionary perspective on immunosenescence. Ann N Y Acad Sci. 2000;908:244-54

7. Shavlakadze T, McGeachie J, Grounds MD. Delayed but excellent myogenic stem cell response of regenerating geriatric skeletal muscles in mice. Biogerontology. 2010;11(3):363-76. doi:10.1007/s10522-009-9260-0.

8. Smythe GM, Shavlakadze T, Roberts P, Davies MJ, McGeachie JK, Grounds MD. Age influences the early events of skeletal muscle regeneration: studies of whole muscle grafts transplanted between young (8 weeks) and old (13-21 months) mice. Exp Gerontol. 2008;43(6):550-62. doi:10.1016/j.exger.2008.02.005.

9. Lepper C, Partridge TA, Fan CM. An absolute requirement for Pax7-positive satellite cells in acute injury-induced skeletal muscle regeneration. Development. 2011:138(17):3639-46. doi:10.1242/dev.067595.

10. Sambasivan R, Yao R, Kissenpfennig A, Van Wittenberghe L, Paldi A, Gayraud-Morel B, et al. Pax7-expressing satellite cells are indispensable for adult skeletal muscle regeneration. Development. 2011;138(17):3647-56. doi:10.1242/dev.067587.

11. von Maltzahn J, Jones AE, Parks RJ, Rudnicki MA. Pax7 is critical for the normal function of satellite cells in adult skeletal muscle. Proc Natl Acad Sci U S A. 2013:110(41):16474-9. doi:10.1073/pnas.1307680110.

12. Brack AS, Rando TA. Tissue-specific stem cells: lessons from the skeletal muscle satellite cell. Cell Stem Cell. 2012;10(5):504-14. doi:10.1016/j.stem. 2012.04.001

13. Chakkalakal JV, Jones KM, Basson MA, Brack AS. The aged niche disrupts muscle stem cell quiescence. Nature. 2012;490(7420):355-60. doi:10.1038/ nature11438.

14. Sousa-Victor P, Gutarra S, Garcia-Prat L, Rodriguez-Ubreva J, Ortet L, RuizBonilla V, et al. Geriatric muscle stem cells switch reversible quiescence into senescence. Nature. 2014;506(7488):316-21. doi:10.1038/nature13013.

15. Bernet JD, Doles JD, Hall JK, Kelly Tanaka K, Carter TA, Olwin BB. p38 MAPK signaling underlies a cell-autonomous loss of stem cell self-renewal in skeletal muscle of aged mice. Nat Med. 2014;20(3):265-71. doi:10.1038/nm.3465.

16. Cosgrove BD, Gilbert PM, Porpiglia E, Mourkioti F, Lee SP, Corbel SY, et al. Rejuvenation of the muscle stem cell population restores strength to injured aged muscles. Nat Med. 2014;20(3):255-64. doi:10.1038/nm.3464.

17. Price FD, von Maltzahn J, Bentzinger CF, Dumont NA, Yin H, Chang NC et al. Inhibition of JAK-STAT signaling stimulates adult satellite cell function. Nature medicine. 2014. doi:10.1038/nm.3655.
18. Tierney MT, Aydogdu T, Sala D, Malecova B, Gatto S, Puri PL et al. STAT3 signaling controls satellite cell expansion and skeletal muscle repair. Nature medicine. 2014. doi:10.1038/nm.3656.

19. Fry CS, Lee JD, Mula J, Kirby TJ, Jackson JR, Liu F, et al. Inducible depletion of satellite cells in adult, sedentary mice impairs muscle regenerative capacity without affecting sarcopenia. Nat Med. 2015;21(1):76-80. doi:10.1038/nm.3710.

20. Brack AS, Bildsoe $H$, Hughes SM. Evidence that satellite cell decrement contributes to preferential decline in nuclear number from large fibres during murine age-related muscle atrophy. J Cell Sci. 2005;118(Pt 20): 4813-21. doi:10.1242/jcs.02602.

21. Harrison DE. Long-term erythropoietic repopulating ability of old, young, and fetal stem cells. The Journal of experimental medicine. 1983:157(5): 1496-504.

22. Carlson BM, Faulkner JA. The regeneration of skeletal muscle fibers following injury: a review. MedSciSports Exercise. 1983;15:187.

23. Brack AS, Rando TA. Intrinsic changes and extrinsic influences of myogenic stem cell function during aging. Stem Cell Rev. 2007;3(3):226-37.

24. Carlson BM, Faulkner JA. Muscle transplantation between young and old rats: age of host determines recovery. The American journal of physiology. 1989;256(6 Pt 1):C1262-6.

25. Grounds MD. Age-associated changes in the response of skeletal muscle cells to exercise and regeneration. Ann N Y Acad Sci. 1998;854(78-91):78-91.

26. Lee AS, Anderson JE, Joya JE, Head SI, Pather N, Kee AJ, et al. Aged skeletal muscle retains the ability to fully regenerate functional architecture. Biogeosciences. 2013;3(2):25-37. doi:10.4161/bioa.24966.

27. Carlson ME, Hsu M, Conboy IM. Imbalance between pSmad3 and Notch induces CDK inhibitors in old muscle stem cells. Nature. 2008:454(7203): 528-32. doi:10.1038/nature07034

28. Elabd C, Cousin W, Upadhyayula P, Chen RY, Chooljian MS, Li J, et al. Oxytocin is an age-specific circulating hormone that is necessary for muscle maintenance and regeneration. Nat Commun. 2014:5:4082. doi:10.1038/ncomms5082.

29. Naito AT, Sumida T, Nomura S, Liu ML, Higo T, Nakagawa A, et al. Complement C1q activates canonical Wnt signaling and promotes aging-related phenotypes. Cell. 2012;149(6):1298-313. doi:10.1016/j.cell.2012.03.047.

30. Paliwal P, Pishesha N, Wijaya D, Conboy IM. Age dependent increase in the levels of osteopontin inhibits skeletal muscle regeneration. Aging (Albany NY). 2012:4(8):553-66.

31. Yousef H, Conboy MJ, Morgenthaler A, Schlesinger C, Bugaj L, Paliwal P, et al. Systemic attenuation of the TGF-beta pathway by a single drug simultaneously rejuvenates hippocampal neurogenesis and myogenesis in the same old mammal. Oncotarget. 2015:6(14):11959-78.

32. Egerman MA, Cadena SM, Gilbert JA, Meyer A, Nelson HN, Swalley SE, et al. GDF11 increases with age and inhibits skeletal muscle regeneration. Cell Metab. 2015;22(1):164-74. doi:10.1016/j.cmet.2015.05.010.

33. Sinha M, Jang YC, Oh J, Khong D, Wu EY, Manohar R, et al. Restoring systemic GDF11 levels reverses age-related dysfunction in mouse skeletal muscle. Science. 2014;344(6184):649-52. doi:10.1126/science. 1251152.

34. Brun CE, Rudnicki MA. GDF11 and the mythical fountain of youth. Cell Metab. 2015;22(1):54-6. doi:10.1016/j.cmet.2015.05.009.

35. Kharraz Y, Guerra J, Pessina P, Serrano AL, Munoz-Canoves P. Understanding the process of fibrosis in Duchenne muscular dystrophy. BioMed research international. 2014;2014:965631. doi:10.1155/2014/965631.

36. Tidball JG, Dorshkind K, Wehling-Henricks $M$. Shared signaling systems in myeloid cell-mediated muscle regeneration. Development. 2014;141(6): 1184-96. doi:10.1242/dev.098285.

37. Salminen A, Kaarniranta K, Kauppinen A. Inflammaging: disturbed interplay between autophagy and inflammasomes. Aging (Albany NY). 2012:4(3):166-75

38. Lemos DR, Babaeijandaghi F, Low M, Chang CK, Lee ST, Fiore D, et al. Nilotinib reduces muscle fibrosis in chronic muscle injury by promoting TNF-mediated apoptosis of fibro/adipogenic progenitors. Nat Med. 2015; 21(7):786-94. doi:10.1038/nm.3869.

39. McCulloch EA, Till JE. The radiation sensitivity of normal mouse bone marrow cells, determined by quantitative marrow transplantation into irradiated mice. Radiat Res. 1960;13:115-25.

40. Till JE, MC CE. A direct measurement of the radiation sensitivity of normal mouse bone marrow cells. Radiat Res. 1961:14:213-22.

41. Collins CA, Zammit PS, Ruiz AP, Morgan JE, Partridge TA. A population of myogenic stem cells that survives skeletal muscle aging. Stem Cells. 2007; 25(4):885-94. doi:10.1634/stemcells.2006-0372. 
42. Garcia-Prat L, Sousa-Victor P, Munoz-Canoves P. Functional dysregulation of stem cells during aging: a focus on skeletal muscle stem cells. The FEBS journal. 2013;280(17):4051-62. doi:10.1111/febs.12221.

43. Sousa-Victor $P$, Garcia-Prat L, Serrano AL, Perdiguero E, Munoz-Canoves $P$. Muscle stem cell aging: regulation and rejuvenation. Trends in endocrinology and metabolism: TEM. 2015;26(6):287-96. doi:10.1016/j.tem.2015.03.006.

44. Kuang S, Kuroda K, Le Grand F, Rudnicki MA. Asymmetric self-renewal and commitment of satellite stem cells in muscle. Cell. 2007;129(5):999-1010. doi:10.1016/j.cell.2007.03.044

45. Rocheteau P, Gayraud-Morel B, Siegl-Cachedenier I, Blasco MA, Tajbakhsh S. A subpopulation of adult skeletal muscle stem cells retains all template DNA strands after cell division. Cell. 2012;148(1-2):112-25. doi:10.1016/j.cell. 2011.11.049.

46. Conboy MJ, Karasov AO, Rando TA. High incidence of non-random template strand segregation and asymmetric fate determination in dividing stem cells and their progeny. PLoS Biol. 2007;5(5), e102. doi:10.1371/journal.pbio.0050102.

47. Zeng W, Lu YH, Lee J, Friedman JM. Reanalysis of parabiosis of obesity mutants in the age of leptin. Proc Natl Acad Sci U S A. 2015;112(29):E3874-82. doi:10.1073/pnas.1510378112.

48. Sun J, Ramos A, Chapman B, Johnnidis JB, Le L, Ho YJ, et al. Clonal dynamics of native haematopoiesis. Nature. 2014;514(7522):322-7. doi:10.1038/nature13824.

49. Hall JK, Banks GB, Chamberlain JS, Olwin BB. Prevention of muscle aging by myofiber-associated satellite cell transplantation. Science translational medicine. 2010;2(57):57ra83. doi:10.1126/scitranslmed.3001081.

50. Vahidi Ferdousi L, Rocheteau P, Chayot R, Montagne B, Chaker Z, Flamant P, et al. More efficient repair of DNA double-strand breaks in skeletal muscle stem cells compared to their committed progeny. Stem Cell Res. 2014; 13(3 Pt A):492-507. doi:10.1016/j.scr.2014.08.005.

51. Fulle S, Di Donna S, Puglielli C, Pietrangelo T, Beccafico S, Bellomo R, et al. Age-dependent imbalance of the antioxidative system in human satellite cells. Exp Gerontol. 2005;40(3):189-97. doi:10.1016/j.exger.2004.11.006.

52. Didier N, Hourde C, Amthor H, Marazzi G, Sassoon D. Loss of a single allele for Ku80 leads to progenitor dysfunction and accelerated aging in skeletal muscle. EMBO Mol Med. 2012:4(9):910-23. doi:10.1002/emmm.201101075.

53. Baj A, Bettaccini AA, Casalone R, Sala A, Cherubino P, Toniolo AQ. Culture of skeletal myoblasts from human donors aged over 40 years: dynamics of cell growth and expression of differentiation markers. J Transl Med. 2005;3(1):21. doi:10.1186/1479-5876-3-21.

54. Bortoli S, Renault V, Eveno E, Auffray C, Butler-Browne G, Pietu G. Gene expression profiling of human satellite cells during muscular aging using CDNA arrays. Gene. 2003;321:145-54.

55. Charge SB, Brack AS, Hughes SM. Aging-related satellite cell differentiation defect occurs prematurely after Ski-induced muscle hypertrophy. Am J Physiol Cell Physiol. 2002;283(4):C1228-41. doi:10.1152/ajpcell.00206.2002.

56. Conboy IM, Conboy MJ, Smythe GM, Rando TA. Notch-mediated restoration of regenerative potential to aged muscle. Science. 2003;302(5650):1575-7. doi:10.1126/science.1087573

57. Day K, Shefer G, Shearer A, Yablonka-Reuveni Z. The depletion of skeletal muscle satellite cells with age is concomitant with reduced capacity of single progenitors to produce reserve progeny. Dev Biol. 2010;340(2):330-43. doi:10. 1016/j.ydbio.2010.01.006.

58. Liu L, Cheung TH, Charville GW, Hurgo BM, Leavitt T, Shih J, et al. Chromatin modifications as determinants of muscle stem cell quiescence and chronological aging. Cell reports. 2013;4(1):189-204. doi:10.1016/j.celrep.2013.05.043.

59. Pietrangelo T, Puglielli $C$, Mancinelli $R$, Beccafico $S$, Fano G, Fulle $S$. Molecular basis of the myogenic profile of aged human skeletal muscle satellite cells during differentiation. Exp Gerontol. 2009;44(8):523-31. doi:10 1016/j.exger.2009.05.002.

60. Baker DJ, Wijshake T, Tchkonia T, LeBrasseur NK, Childs BG, van de Sluis B, et al. Clearance of p16lnk4a-positive senescent cells delays ageingassociated disorders. Nature. 2011;479(7372):232-6. doi:10.1038/nature10600

61. Sousa-Victor P, Perdiguero E, Munoz-Canoves P. Geroconversion of aged muscle stem cells under regenerative pressure. Cell Cycle. 2014;13(20): 3183-90. doi:10.4161/15384101.2014.965072.

62. Juan AH, Derfoul A, Feng X, Ryall JG, Dell'Orso S, Pasut A, et al. Polycomb EZH2 controls self-renewal and safeguards the transcriptional identity of skeletal muscle stem cells. Genes Dev. 2011;25(8):789-94. doi:10.1101/gad. 2027911.

63. Le Roux I, Konge J, Le Cam L, Flamant P, Tajbakhsh S. Numb is required to prevent p53-dependent senescence following skeletal muscle injury. Nat Commun. 2015;6:8528. doi:10.1038/ncomms9528.
64. Chakkalakal JV, Christensen J, Xiang W, Tierney MT, Boscolo FS, Sacco A, et al. Early forming label-retaining muscle stem cells require p27kip1 for maintenance of the primitive state. Development. 2014;141(8):1649-59. doi: 10.1242/dev.100842.

65. Shea KL, Xiang W, LaPorta VS, Licht JD, Keller C, Basson MA, et al. Sprouty1 regulates reversible quiescence of a self-renewing adult muscle stem cell pool during regeneration. Cell Stem Cell. 2010;6(2):117-29. doi:10.1016/j. stem.2009.12.015.

66. Bigot A, Duddy WJ, Ouandaogo ZG, Negroni E, Mariot V, Ghimbovschi S, et al. Age-associated methylation suppresses SPRY1, leading to a failure of re-quiescence and loss of the reserve stem cell pool in elderly muscle. Cell reports. 2015. doi:10.1016/j.celrep.2015.09.067.

67. Goh LK, Sorkin A. Endocytosis of receptor tyrosine kinases. Cold Spring Harbor perspectives in biology. 2013;5(5):a017459. doi:10.1101/cshperspect. a017459.

68. Franceschi C, Campisi J. Chronic inflammation (inflammaging) and its potential contribution to age-associated diseases. J Gerontol Ser A Biol Med Sci. 2014;69 Suppl 1:S4-9. doi:10.1093/gerona/glu057.

69. Kodama R, Kato M, Furuta S, Ueno S, Zhang Y, Matsuno K, et al. ROSgenerating oxidases Nox1 and Nox4 contribute to oncogenic Ras-induced premature senescence. Genes to cells: devoted to molecular \& cellular mechanisms. 2013;18(1):32-41. doi:10.1111/gtc.12015.

70. Lee AC, Fenster BE, Ito H, Takeda K, Bae NS, Hirai T, et al. Ras proteins induce senescence by altering the intracellular levels of reactive oxygen species. The Journal of biological chemistry. 1999;274(12):7936-40.

71. Mandal PK, Blanpain C, Rossi DJ. DNA damage response in adult stem cells: pathways and consequences. Nat Rev Mol Cell Biol. 2011;12(3):198-202. doi: 10.1038/nrm3060.

72. Ramsey MR, Sharpless NE. ROS as a tumour suppressor? Nat Cell Biol. 2006; 8(11):1213-5. doi:10.1038/ncb1106-1213.

73. Shao L, Li H, Pazhanisamy SK, Meng A, Wang Y, Zhou D. Reactive oxygen species and hematopoietic stem cell senescence. Int J Hematol. 2011;94(1): 24-32. doi:10.1007/s12185-011-0872-1.

74. Cerletti M, Jang YC, Finley LW, Haigis MC, Wagers AJ. Short-term calorie restriction enhances skeletal muscle stem cell function. Cell Stem Cell. 2012; 10(5):515-9. doi:10.1016/j.stem.2012.04.002.

75. Charville GW, Cheung TH, Yoo B, Santos PJ, Lee GK, Shrager JB, et al. Ex vivo expansion and in vivo self-renewal of human muscle stem cells. Stem cell reports. 2015;5(4):621-32. doi:10.1016/j.stemcr.2015.08.004.

\section{Submit your next manuscript to BioMed Central and we will help you at every step:}

- We accept pre-submission inquiries

- Our selector tool helps you to find the most relevant journal

- We provide round the clock customer support

- Convenient online submission

- Thorough peer review

- Inclusion in PubMed and all major indexing services

- Maximum visibility for your research

Submit your manuscript at www.biomedcentral.com/submit
Biomed Central 